\title{
Comparative studies of vertebrate aldehyde dehydrogenase 3: Sequences, structures, phylogeny and evolution. Evidence for a mammalian origin for the ALDH3A1 gene
}

\author{
Roger S Holmes*1 and John Hempel ${ }^{2}$
}

\begin{abstract}
'School of Biomolecular and Physical Sciences, Griffith University, Nathan 4111 Brisbane Queensland Australia Email: r.holmesegriffith.edu.au *Corresponding Author: Tel: +61-7-33482834

${ }^{2}$ Department of Biological Sciences, University of Pittsburgh, Pittsburgh PA USA
\end{abstract}

\section{ABSTRACT}

Mammalian ALDH3 genes ( $A L D H 3 A 1, A L D H 3 A 2, A L D H 3 B 1$ and $A L D H 3 B 2$ ) encode enzymes of peroxidic and fatty aldehyde metabolism. ALDH3Al also plays a major role in anterior eye tissue UV-filtration. BLAT and BLAST analyses were undertaken of several vertebrate genomes using rat, chicken and zebrafish ALDH3-like amino acid sequences. Predicted vertebrate ALDH3 sequences and structures were highly conserved, including residues involved in catalysis, coenzyme binding and enzyme structure as reported by Liu and coworkers (1997) for rat ALDH3A1. Phylogeny studies of human, rat, opossum, platypus, chicken, xenopus and zebrafish ALDH3-like sequences supported three hypotheses: (1) the mammalian ALDH3A1 gene was generated by a tandem duplication event of an ancestral vertebrate ALDH3A2 gene; (2) multiple mammalian and chicken ALDH3Blike genes were generated by tandem duplication events within genomes of related species; and (3) vertebrate $A L D H 3 A$ and $A L D H 3 B$ genes were generated prior to the appearance of bony fish more than 500 million years ago.

Key words: aldehyde dehydrogenase; ALDH3; enzyme structure; gene duplication; evolution; aldehyde metabolism

\section{Introduction}

The aldehyde dehydrogenase (ALDH; EC 1.2.1.3) gene super-family (http://aldh.org/superfamily.php) encodes many ALDHs which perform diverse roles in aldehyde metabolic pathways in the body, including retinoid, lipid, alcohol, amino acid, neurotransmitter, xenobiotic and drug metabolism [1,2]. The mammalian ALDH3 gene family has been investigated predominantly because of the roles of ALDH3 isozymes in fatty and peroxidic aldehyde metabolism, and the high ALDH3 activity 
levels in cornea, stomach, hepatomas and liver microsomes [3-8]. Four major mammalian ALDH3-like genes and enzymes have been reported including ALDH3A1, which encodes the major corneal, stomach, and hepatoma isozyme [4-6] and acts in corneal UV-filtration [7-8]; ALDH3A2, which encodes the liver microsomal fatty aldehyde dehydrogenase [9,10], which has been implicated in the Sjögren-Larsson syndrome [11]; ALDH3B1, encoding a human lung, prostate and kidney cytosolic ALDH [12,13]; and ALDH3B2, encoding a human salivary gland and placental ALDH [14].

This study describes the predicted sequences, structures and phylogeny of vertebrate ALDH3 genes and enzymes for platypus (Ornithorhynchus anatinus), chicken (Gallus gallus), frog (Xenopus tropicalis) and zebrafish (Danio rerio), and compares these results to those previously reported for human (Homo sapiens), rat (Rattus norvegicus) and other mammalian ALDH3 isozymes. Structures for vertebrate ALDH3 isozymes and gene locations for ALDH3-like genes were obtained using data from the respective genome sequences. This paper extends previous studies which examined the structures and properties of opossum (Monodelphis domestica) ALDH3-like genes and proteins [15,16]. Phylogenetic analyses also describe the relationships and potential origins of ALDH3A-like and ALDH3B-like genes during mammalian and vertebrate evolution.

\title{
2. Materials and methods
}

\author{
2.1 Vertebrate ALDH3 Gene and Enzyme Identification
}

BLAT (BLAST-Like Alignment Tool) in silico studies were undertaken using the UC Santa Cruz genome browser [http://genome.ucsc.edu/cgi-bin/hgBlat] [17, 18] with the default settings. GenBank [http://www.ncbi.nlm.nih.gov/Genbank/] and UniProtKB/Swiss-Prot Database [http://au.expasy.org] sequences for rat ALDH3A1, ALDH3A2, ALDH3B1 and ALDH3B2 (Table 1) were used to interrogate platypus 
(Ornithorhynchus anatinus), chicken (Gallus gallus), frog (Xenopus tropicalis) and zebrafish (Danio rerio) genome sequences [19-22]. Gene locations, predicted gene structures and ALDH3 protein subunit sequences were observed for each ALDH examined for those regions showing identity with the respective ALDH gene products (Table 1). Unless otherwise stated, all residue numbering is as in [27], according to the rat ALDH3A1 sequence.

2.2 Alignment of Vertebrate ALDH3 Residues

Alignments of human ALDH3A1 [23], ALDH3A2 [11], ALDH3B1 [12] and ALDH3B2

[14], rat ALDH3A1 [4] and of other predicted vertebrate ALDH3A1, ALDH3A2, ALDH3B1 and ALDH3B2 sequences (see Tables 1 \& 2) were undertaken using a ClustalW-technique [24] (http://www.ebi.ac.uk/clustalw/).

2.3 Predicted Secondary and Tertiary structures for Human ALDH3A1, ALDH3A2, ALDH3B1 and ALDH3B2 Subunits

Predicted secondary and tertiary structures for human ALDH3A1, ALDH3A2, ALDH3B1 and ALDH3B2 subunits were obtained using web tools $[25,26]$

(http://swissmodel.expasy.org/workspace). The tertiary structure for rat ALDH3A1 [27] served as a reference for obtaining these tertiary structures: human ALDH3A1 (residues 4-448); ALDH3A2 (residues 5-443), ALDH3B1 (residues 5-446) and ALDH3B2 (residues 4-366) using the rat ALDH3A1 template at $2.6 \AA$ resolution (PDB ID $1 \mathrm{ad} 3 \mathrm{~B})$.

2.4 Prediction of Transmembrane Regions for Vertebrate ALDH3 Predictions of transmembrane helices for human, rat, platypus, chicken, frog and zebrafish ALDH3 sequences were conducted using the web resources of the Center for Biological Sequence Analysis, Technical University of Denmark TMHMM Server v. 2.0 (http://www.cbs.dtu.dk/services/TMHMM/).

2.5 Phylogenetic Studies and Sequence Divergence 
Alignments of vertebrate ALDH3 sequences with the nematode (C. elegans) ALDH3 sequence as the 'outgroup' were assembled using BioEdit v.5.0.1 and the default settings [28]. Alignment of ambiguous regions, including the amino and carboxyl termini, were excluded prior to phylogenetic analysis yielding alignments of 261 residues for comparisons of vertebrate ALDH3A1, ALDH3A2, ALDH3B1 and ALDH3B2 sequences (Tables 1 \& 2). Evolutionary distances were calculated using the Kimura option [29] in TREECON [30]. Phylogenetic trees were constructed from evolutionary distances using the neighbor-joining method [31] and rooted with the $C$. elegans ALDH3 sequence (Reference Sequence NM_071144). Tree topology was reexamined by the boot-strap method (100 bootstraps were applied) of resampling and only values that were highly significant $(\geq 90)$ are shown [32]. Percentage sequence identities for the ALDH3 family subunits examined were determined using the SIM-Alignment tool for Protein Sequences [26] (http://au.expasy.org/tools/sim-prot.html).

\section{Results and Discussion}

\subsection{Alignments of rat and human ALDH3A1, human ALDH3A2, ALDH3B1 and ALDH3B2} and vertebrate ALDH3B2 amino acid sequences

Amino acid sequence alignments for rat ALDH3A1 [4] and human ALDH3A1 [23], ALDH3A2 [11], ALDH3B1 [12] and ALDH3B2 [14] are shown in Figure 1. Comparisons of the latter four ALDH sequences with the rat ALDH3Al sequence (tertiary structure previously reported) [27] enabled identification of key residues which may contribute to catalysis, structure and function. Table 3 identifies some of these key residues for vertebrate ALDH3A1, ALDH3A2, ALDH3B1 and ALDH3B2 sequences and the nematode (C. elegans) ALDH3-like sequence. Active site residues which are considered essential for catalysis (Asn114; Glu209; Cys243; Glu 333) [27, 33, 34] were conserved for all of these ALDH3 sequences. Fifteen glycine residues were also retained for all of these ALDH3 sequences examined 
(Table 3) which is consistent with the roles proposed by Hempel and coworkers [33] in contributing to the structure of rat ALDH3A1. Two of these conserved residues (Gly187 and Gly211) are located within the stem of the active site funnel. Three proline residues were also retained (Pro103, 317 and 340) which appear to contribute significantly to rat ALDH3A1 tertiary structure [27]. In addition, a novel dinucleotide-binding motif and NAD(P) binding domain near the N-terminal end of the $\alpha$ D helix (188Gly-Ser-Thr-Ala-Val-193Gly) [27] was predominantly retained for the human ALDH3A1, ALDH3A2, ALDH3B1 and ALDH3B2 sequences (Figure 1).

Amino acid sequence alignments for human ALDH3B1 [12] with mammalian and chicken ALDH3B2-like amino acid sequences (Table 2) are shown in Figure sl (see supplementary data). Essential ALDH3 active site, nucleotide phosphate binding and structural glycine and proline residues were predominantly retained for each of the vertebrate ALDH3B2 sequences examined, although major differences in sequence length were observed, particularly for the primate ALDH3B2 sequences, which lacked 81 residues of the N-terminal sequence. In addition, the horse ALDH3B2 sequence lacked a hydrophobic residue near the active site Asn114 (Phe118 in rat ALDH3A1) and four residues near the active site Cys residue (Cys243 in rat ALDH3A1). Also, chicken ALDH3B2 revealed two major deleted segments in comparison with the human ALDH3B1 sequence but retained other key ALDH3A1 residues.

Sequence identities for vertebrate ALDH3-like sequences were examined (see Table S1 in supplementary data) with high levels of sequence identities observed for the human, rhesus monkey, rat, opossum and platypus ALDH3A1 sequences (8098\%). Comparisons of sequence identities between human, rhesus monkey, rat, opossum, platypus, chicken, frog and zebrafish ALDH3A2 sequences were also examined, with 66-96\% identities being observed as well as high levels of identity for more closely related species (eg. human and rhesus monkey ALDH3A2 
were 96\% identical). Lower pairwise identities were observed between ALDH3A1 and ALDHA2 sequences from the same mammalian species (69-73\%), and in comparing ALDH3A1 and ALDH3A2 sequences with the human ALDH3B1 and ALDH3B2 sequences (5057\%). This supports a proposal that the identified vertebrate ALDH sequences are members of the ALDH3 family but are products of the same ALDH3 gene sub-class in each case (Table S1).

\subsection{Predicted Structures for Human ALDH3A1, ALDH3A2, ALDH3B1 and ALDH3B2}

Predicted secondary structures for human ALDH3A2, ALDH3B1 and ALDH3B2 subunits were compared in Figure 1 with the previously reported structure for rat ALDH3A1 [27]. Similar $\alpha$-helix and $\beta$-strand locations were observed for each of the ALDH3 subunits examined. The most significant difference related to the extra $\alpha$-helix at the carboxy-terminus for the human ALDH3A2 sequence, which showed a high probability as a transmembrane sequence which was also observed for the chicken ALDH3A2 sequence (Figure 2). Given the reported location of human and mouse ALDH3A2 within the liver endoplasmic reticulum [3,9], and the fact that the c-termini occur on the same face of the dimer [27, 35], it is likely that this sequence is responsible for the membrane-bound location for this enzyme. In contrast, human ALDH3A1, ALDH3B1 and ALDH3B2 sequences showed only low probability regions for transmembrane sequences, which supports their location within the cytoplasm, as previously reported for rat ALDH3A1 [4,33]. Moreover, ALDH3Al serves as a major soluble or 'crystallin-like' corneal protein for several mammals, and acts as a UV-filtering agent, protecting anterior eye tissues from UV-induced damage $[7,8,36]$.

Predicted tertiary structures for human ALDH3A1, ALDH3A2, ALDH3B1 and ALDH3B2 were compared with rat ALDH3A1 [27] (Figure 3). Similar structures were observed for each enzyme, including the 3 major domains: the catalytic domain and the NAD binding domain, which are separated by the active site cleft, and an oligomerisation domain, which is involved in forming dimers of the active enzyme 
[27]. The predicted human ALDH3B2 tertiary structure, however, showed a more open conformation, apparently resulting from the loss of three helices at the Nterminus $(\alpha 1-\alpha 3)$, in comparison with the human ALDH3A1 structure (Figure 3 ). 3.3 Predicted gene locations and exonic structures for vertebrate ALDH3-like genes

Tables 1 and 2 summarize the predicted locations, sizes and number of coding exons for vertebrate ALDH3A-like and ALDH3B-like genes examined, respectively. These were based on BLAST interrogations of ALDH3-like transcript databases (http://blast.ncbi.nlm.nih.gov/Blast.cgi) using the reported sequences for rat and mouse ALDH3A1 [4,37], ALDH3A2 [9], ALDH3B1 and ALDH3B2 [38], chicken ALDH3A2 [39] and zebrafish ALDH3A2 [22] and BLAT analyses of vertebrate and nematode (Caenorhabditis elegans) genomes using the UC Santa Cruz Genome Browser [18] (http://genome.ucsc.edu/cgi-bin/hgBlat).

Mammalian ALDH3A1 and ALDH3A2 genes were located between 26 (mouse) and 141 (opossum) kilobases apart on the same chromosome (or shotgun contig for guinea pig, cat and platypus genomes) but were usually encoded on opposite strands and contained 9 or 10 coding exons (Table 1). ALDH3A2 genes were typically 3-4 times larger than ALDH3Al genes and identified in all vertebrate genomes examined, whereas ALDH3Al genes are apparently restricted to mammalian genomes, including marsupial [opossum (Monodelphis domestica)] and monotreme [platypus (Ornithorynchus anatinus)] species.

Mammalian ALDH3B1 and ALDH3B2 genes were also located on the same chromosome (but different from the ALDH3A genes), and were 43 (guinea pig) to 349 (human) kilobases apart and also encoded on opposite strands with 7-10 coding exons (Table 2). Mammalian ALDH3Bl genes were typically $3-5$ times larger than for the ALDH3B2 genes. Single ALDH3B-like genes were identified in lower vertebrate genomes, including frog (Xenopus tropicalis) and several fish genomes 
(eg Danio rerio), which were designated as ALDH3Bl genes for consistency with the chicken and mammalian gene nomenclature

Predicted start sites for 10 coding exons were identified for the rat and human ALDH3A1 and human ALDH3A2 genes, which were located in similar or aligned positions in each case, with the exception of the exon 9/10 boundary, for which an extended ALDH3A2 exon 9 sequence was observed (Figure 1). Comparisons of coding exons for the human ALDH3B1 and ALDH3B2 sequences revealed similarities, with the exception of coding exons 1 and 2 and the last exon boundary for the human ALDH3B1 sequence, which were absent from the human ALDH3B2 sequence.

\subsection{Phylogeny and evolution of vertebrate ALDH3A and ALDH3B sequences}

A phylogram (Figure 4) was calculated by the progressive alignment of vertebrate ALDH3 amino acid sequences with a nematode (C. elegans) ALDH3-like sequence used to 'root' the tree, which clustered into three main branches, corresponding to the ALDH3A1-like, ALDH3A2-like and ALDH3B-like proteins and genes. The observed ALDH3A1 sequences were restricted to mammals, including marsupial (opossum) [16] and monotreme (platypus) species, whereas ALDH3A2-like sequences were observed for all vertebrates examined, including several bony fish species. The tandem locations of mammalian ALDH3A-like genes (Table 1), the higher levels of identities for ALDH3A1 and ALDH3A2 sequences (>69\%) (Table S1) and the phylogram generated from calculating genetic distances for vertebrate ALDH3A-like sequences (Figure 4) support an hypothesis that mammalian ALDH3Al genes were generated by a tandem duplication of a vertebrate ancestral $A L D H 3 A$ gene, prior to the emergence of mammals during vertebrate evolution.

In contrast, mammalian and chicken ALDH3B1 and ALDH3B2 sequences grouped together on single branches of the phylogram, indicating that these genes are products of recent species (or related species) gene duplication events of an ancestral vertebrate $A L D H 3 B$ gene. This is further supported by the tandem locations for these genes on mammalian and chicken chromosomes and the high 
level (88\%) of amino acid sequence identity for the human ALDH3B1 and ALDH3B2 sequences (Table Sl). In addition, given that fish genomes contained both ALDH3A- and ALDH3B-like genes, these results also support an hypothesis that the common ancestor for ALDH3 genes predated the evolutionary appearance vertebrates, which has been estimated at >500 million years ago [40].

\subsection{Functions of Vertebrate ALDH3 Isozymes}

Several metabolic roles have been previously described for mammalian ALDH3A1 (Table 4). These include serving as a detoxifying agent for peroxidic aldehydes in the body [41,42]; a multifunctional protein in the eye, including roles as a corneal and lens 'crystallin' in several mammalian species [36]; a protective agent against oxidative damage in the lens and cornea [43]; a UV-radiation filter in mammalian anterior eye tissues [6-8,44-46]; in cyclophosphamide and related cancer drug metabolism [47]; as well as participating in the oxidative stress response and cell homeostasis [48].

Human ALDH3A2 (also called fatty aldehyde dehydrogenase) plays a major role in the body in the metabolism of long chain fatty aldehydes and several genetic mutations have been reported in human populations which lead to the recessive Sjögren-Larsson syndrome (SLS) [10,11]. One of the numerous mutations which gives rise to the SLS involves Asp-247 [33]. Asp-247 is conserved in all ALDH3s considered here, with the exception of a conservative Glu substitution in the chicken 3 Bl enzyme. Mammalian ALDH3A2 is predominantly located within liver microsomes [3], via a hydrophobic C-terminal transmembrane helix [9], a property which is also shared with chicken ALDH3A2 (Figure 2).

The metabolic role(s) for the ALDH3B-like genes and proteins have not been described in mammals, however it is likely that they perform 
detoxification roles for endogenous and exogenous aldehydes in the body, particularly in the adrenals and lung ( $A L D H 3 B I$ ) and the epidermis (ALDH3B2), where these genes exhibit high levels of expression [12-14] However, deletions in various ALDH3B2 sequences (eg human, chimpanzee, rhesus, horse and chicken ALDH3B2) raise questions concerning their functional viability.

\section{Conclusions}

BLAST and BLAT analyses of several vertebrate genome databases were undertaken using amino acid sequences reported for rat ALDH3A1, ALDH3A2 and ALDH3B1, and for chicken and zebrafish ALDH3A2 enzymes, for interrogation of vertebrate genomes. Evidence is presented for at least four ALDH3-like genes in mammalian genomes, including two pairs of closely localized genes on separate chromosomes: [ALDH3A1-ALDH3A2] and [ALDH3B1-ALDH3B2]. Predicted amino acid sequences and secondary/tertiary structures for the vertebrate ALDH3-like subunits showed a high degree of similarity with rat ALDH3Al, which served as a reference structure for these ALDH isozymes [27]. Phylogenetic analyses supported three hypotheses concerning the molecular evolution of vertebrate ALDH3-like genes: (1) the mammalian ALDH3A1 gene was generated by a tandem duplication event of an ancestral vertebrate ALDH3A2 gene; (2) multiple mammalian and chicken ALDH3B-like genes were generated by tandem duplication events within genomes of related species; and (3) vertebrate ALDH3A and ALDH3B genes were generated within an ancestral genome, prior to the appearance of bony fish, more than 500 million years ago [40].

Conflict of interest statement

None

\section{Acknowledgements}


We are grateful to Dr Laura Cox and Dr John VandeBerg of the Southwest Foundation for Biomedical Research in San Antonio Texas for helpful advice and to Dr Bharet Patel of the School of Biomolecular and Physical Sciences, Griffith University in Brisbane Australia for his assistance with the phylogenetic studies.

\section{References}

[1] Vasiliou V, Nebert DW (2005) Analysis and update of the human aldehyde dehydrogenase (ALDH) gene family. Human Genomics 2:138-145

[2] Sophos NA, Black WJ, Vasiliou V (2006) An update of the ALDH gene family. In: Enzymology and Molecular Biology of Carbonyl Metabolism. Eds: $\mathrm{H}$ Weiner, $\mathrm{B}$ Plapp, $\mathrm{R}$ Lindahl E Maser Purdue University Press, Indiana 12:3-7

[3] Timms GP, Holmes RS (1981) Genetics and ontogeny of aldehyde dehydrogenase isozymes in the mouse; evidence for a locus controlling the inducibility of the liver microsomal isozymes. Biochem Genet 19:122-336

[4] Jones DE, Brennan MD, Hempel J, Lindahl R (1988) Cloning and complete nucleotide sequence of a full-length CDNA encoding a catalytically functional tumor-associated aldehyde dehydrogenase. Proc. Natl. Acad. Sci. USA 85:1782-1786

[5] Holmes RS, Popp RA, VandeBerg JL (1988) Genetics of ocular NADdependent alcohol dehydrogenase and aldehyde dehydrogenase in the mouse: evidence for genetic identity with stomach isozymes and localization of Ahd-4 on chromosome 11 near Trembler Biochem Genet $26: 191-205$

[6] Boesch JS, Lee C, Lindahl RG (1996) Constitutive expression of class 3 aldehyde dehydrogenase in cultured rat corneal epithelium. J Biol Chem 271: $5150-5157$

[7] Abedinia M, Pain T, Algar EM, Holmes RS (1990) Bovine corneal aldehyde dehydrogenase: the major soluble protein with a possible dual protective role for the eye. Exp Eye Res 51:419-426

[8] Lassen N, Bateman JB, Estev T, Kuszak JR, Nees DW, Piatigorsky J, Deuster G, Day BJ, Huang J, Hines LM, Vasiliou V (2007) Multiple and additive functions of ALDH3A1 and ALDH1A1: cataract phenotype and ocular oxidative damage in aldh3al(-/-) /aldhlal(-/-) knockout mice. J Biol Chem 282:25668-25676

[9] Miyauchi K, Masaki R, Taketani S, Yamamoto A, Akayama M, Tashiro Y (1991) Molecular cloning, sequencing and expression of cDNA for rat liver microsomal aldehyde dehydrogenase. J Biol Chem 266: 19536-19542

[10] Rogers GR, Marlova NG, De Laurenzi V, Rizzo WB, Compton JG (1997) Genomic organization and expression of the fatty aldehyde dehydrogenase gene (FALDH). Genomics 39:127-135

[11] De Laurenzi V, Rogers GR, Hamrock DJ, Marekov LN, Steinhart PM, Compton JN, Markova N, Rizzo WB (1996) Sjogren-Larsson syndrome is caused by mutations in the fatty aldehyde dehydrogenase gene. Nature Genet 12:52-57

[12] Hsu LC, Chang WC, Hiraoka L, Hsieh CL (1994) Molecular cloning, genomic organization and chromosomal localization of an additional human aldehyde dehydrogenase, ALDH6. Genomics 24:333-341 
[13] Hsu L, Chang W-C, Yoshida A (1994) Sequencing and expression of the human ALDH8 encoding a new member of the aldehyde dehydrogenase family. Gene 151:285-289

[14] Hsu L, Chang W-C, Yoshida A (1997) Human aldehyde dehydrogenase genes, ALDH7 and ALDH8: Genomic organization and gene structure comparison. Gene 189:89-94

[15] Holmes RS (2009) Opossum aldehyde dehydrogenases. Evidence for four ALDH1A1-like genes on chromosome 6 and ALDH1A2 and ALDH1A3 genes on chromosome 1. Biochem Genet 47:609-624

[16] Holmes RS (2010) Biochemical genetics of opossum aldehyde dehydrogenase 3: evidence for three ALDH3A-like genes and an ALDH3B-like gene. Biochem Genet 48: 287-303

[17] Altschul SF, Gish W, Miller W, Myers EW, Lipman DJ (1990) Basic local alignment search tool. J Mol Biol 215:403-410

[18] Kent WJ, Sugnet CW, Furey TS, Roskin KM, Pringle TH, Zahler AM, Haussler D (2003) The human genome browser at UCSC. Genome Res 12: 9941006

[19] Warren WC, Hillier LW, Marshall Graves JA, Birney E, Ponting CP, Grützner $F$, Belov K, Miller W, Clarke L, Chinwalla AT, Yang SP, Heger A, Locke DP, Miethke P, Waters PD, Veyrunes F, Fulton L, Fulton B, Graves T, Wallis J, Puente XS, López-Otín C, Ordóñez GR, Eichler EE, Chen L, Cheng Z, Deakin JE, Alsop A, Thompson K, Kirby P, Papenfuss AT, Wakefield MJ, Olender T, Lancet D, Huttley GA, Smit AF, Pask A, TempleSmith P, Batzer MA, Walker JA, Konkel MK, Harris RS, Whittington CM, Wong ES, Gemmell NJ, Buschiazzo E, Vargas Jentzsch IM, Merkel A, Schmitz J, Zemann A, Churakov G, Kriegs JO, Brosius J, Murchison EP, Sachidanandam R, Smith C, Hannon GJ, Tsend-Ayush E, McMillan D, Attenborough R, Rens W, Ferguson-Smith M, Lefèvre CM, Sharp JA, Nicholas KR, Ray DA, Kube M, Reinhardt R, Pringle TH, Taylor J, Jones RC, Nixon B, Dacheux JL, Niwa H, Sekita Y, Huang X, Stark A, Kheradpour P, Kellis M, Flicek P, Chen Y, Webber C, Hardison R, Nelson J, Hallsworth-Pepin K, Delehaunty K, Markovic C, Minx P, Feng Y, Kremitzki C, Mitreva M, Glasscock J, Wylie T, Wohldmann P, Thiru P, Nhan MN, Pohl CS, Smith SM, Hou S, Nefedov M, de Jong PJ, Renfree MB, Mardis ER, Wilson RK (2008) Genome analysis of the platypus reveals unique signatures of evolution. Nature 453: 175-183

[20] The International Chicken Genome Sequencing Consortium (2004) Sequence and comparative analysis of the chicken genome provide unique perspectives on vertebrate evolution. Nature 432: 695-716

[21] Hellsten U, Harland RM, Gilchrist MJ, Hendrix D, Jurka J, Kapitonov V, Ovcharenko I, Putnam NH, Shu S, Taher L, Blitz IL, Blumberg B, Dichmann DS, Dubchak I, Amaya E, Detter JC, Fletcher R, Gerhard DS, Goodstein D, Graves T, Grigoriev IV, Grimwood J, Kawashima T, Lindquist E, Lucas SM, Mead PE, Mitros $\mathrm{T}$, Ogino $\mathrm{H}$, Ohta $\mathrm{Y}$, Poliakov AV, Pollet N, Robert J, Salamov A, Sater AK, Schmutz J, Terry A, Vize PD, Warren WC, Wells D, Wills A, Wilson RK, Zimmerman LB, Zorn AM, Grainger R, Grammer $T$, Khokha MK, Richardson PM, Rokhsar DS (2010) The Genome of the Western Clawed Frog Xenopus tropicalis. Science 328: 633-636

[22] The Danio rerio Sequencing Project (2008) http://www.sanger.ac.uk/Projects/D_rerio/Zv8_assembly_information.s html

[23] Hsu LC, Chang W-C, Shibuya A, Yoshida A (1992) Human stomach aldehyde dehydrogenase cDNA and genomic cloning, primary structure, and expression in Escherichia coli. J Biol Chem 267:3030-3037 [24] Chenna R, Sugawara H, Koike T, Lopez R, Gibson TJ, Higgins DG, Thompson JD (2003) Multiple sequence alignment with the Clustal series of programs. Nucleic Acids Res 31:3497-3500 
[25] McGuffin LJ, Bryson $K$, Jones DT (2000) The PSIPRED protein structure prediction server. Bioinformatics 16:404-405

[26] Schwede T, Kopp J, Guex N, Peitsch MC (2003) SWISS-MODEL: an automated protein homology-modelling server. Nucleic Acids Res $31: 3383-3385$

[27] Liu Z-J, Sun YJ, Rose JP, Chung Y-J, Hsiao CD, Chang W-R, Kuo I, Perozich J, Lindahl R, Hempel J, Wang B-C (1997). The first structure of an aldehyde dehydrogenase reveals novel interactions between NAD and the Rossmann fold. Nature struct Biol 4:317-326

[28] Hall TA (1999) BioEdit: a user-friendly biological sequence alignment editor and analysis program for Windows 95/98/NT. Nucleic Acids Symp Ser $41: 95-98$

[29] Kimura M (1983) The neutral theory of molecular evolution. Cambridge University Press, Cambridge

[30] Van De Peer Y, de Wachter R (1994) TreeCon for Windows: a software package for the construction and drawing of evolutionary trees for the Microsoft Windows environment. Comput Appl Sci 10:569-570

[31] Saitou N, Nei M (1987) The neighbour-joining method: a new method for reconstructing phylogenetic trees. Mol Biol Evol 4:406-425

[32] Felsenstein J (1985) Confidence limits on phylogenies: an approach using the bootstrap. Evolution 39:783-791

[33] Hempel J, Kuo I, Perozich J, Wang B-C, Lindahl R, Nicholas H (2001) ALDH: maintaining critical active site geometry at motif 8 in the class 3 enzyme. Eur J Biochem 268:722-726

[34\} Wymore T, Hempel J Cho SS, Mackerell AD Jr, Nicholas HB Jr, Deerfield, DW II (2004) Molecular recognition of aldehydes by aldehyde dehydrogenase and mechanism of nucleophilic activation: Proteins: Struct Func Bioinformat 57:758-771.

[35] Hempel J, Stanley S, Perozich J, Wymore T, Nicholas HBJr. (2006) Residue Conservations in Aldehyde Dehydrogenase Gene Fusion Products Reemphasize Functional Interpretations. Pp 8-14 in Enzymology and Molecular Biology of Carbonyl Metabolism 12, Weiner, H., B. Plapp, R. Lindahl, and E. Maser, Ed. Purdue University Press, Lafayette, IN

[36] Jester JV, Moller-Pedersen T, Huang J, Sax CM, Kays WT, Cavangh HD, Petroll WM, Piatigorsky J (1999) The cellular basis of corneal transparency: evidence for 'corneal crystallins'. J Cell Science $112: 613-622$

[37] Vasiliou V, Reuter SF, Williams S, Puga A, Nebert DW (1999) Mouse cytosolic class 3 aldehyde dehydrogenase (Aldhlal): gene structure and regulation of constitutive and dioxine-inducible expression. Pharmacogenetics 9:569-580

[38] Mammalian Gene Collection Team (2004) The status, quality and expansion of the NIH full-length cDNA project: the Mammalian Gene Collection. Genome Res 14:2121-2127

[39] Caldwell RB, Kierzek AM, Arakawa H, Bezzubov Y, Zaim J, Fiedler P, Kutter S, Blagodatski A, Kostovska D, Koter M, Plachy J, Carninci P, Hayashizaki Y, Buerstedde JM (2005) Full-length cDNAs from chicken bursal lymphocytes to facilitate gene function analysis. Genome Biol. 6:R6-R6

[40] Kumar S, Hedges SB (1998) A molecular timescale for vertebrate evolution. Nature 392:917-920

[41] Algar EM, Holmes RS (1989) Purification and properties of mouse stomach aldehyde dehydrogenase. Evidence for a role in the oxidation of peroxidic and aromatic aldehydes. Biochim Biophys Acta 995:168-173

[42] Evces S, Lindahl R (1989) Characterization of rat cornea aldehyde dehydrogenase. Arch Biochem Biophys 274:518-24 
[43] Shiao T, Tran P, Siegel D, Lee J, Vasiliou V (1999) Four amino acid changes are associated with the Aldh3al locus polymorphism in mice which may be responsible for corneal sensitivity to ultraviolet light. Pharmacogenet 9:145-53

[44] King G, Holmes RS (1998) Human ocular aldehyde dehydrogenase isozymes: distribution and properties as major soluble proteins in cornea and lens. J Exp Zool 282:12-17

[45] Pappa A, Estey T, Manzer R, Brown D, Vasiliou V (2003) Human aldehyde dehydrogenase 3A1 (ALDH3A1): biochemical characterization and immunohistochemical localization in the cornea. Biochem $\mathrm{J}$ $376: 615-623$

[46] Pappa A, Brown D, Koutalos Y, DeGregory J, White C, Vasilou, V (2005) Human aldehyde dehydrogenase 3A1 inhibits proliferation and promotes survival of human corneal epithelial cells. J Biol Chem $280: 27998-28006$

[47] Sladek NE (2003) Human aldehyde dehydrogenases: potential pathological, pharmacological and toxilogical impact. J Biochem Mol Toxicol 17:7-23

[48] Moreb JS, Baker HV, Chang L-J, Amaya M, Lopez MC, Ostmark B, Chou W (2008) ALDH isozymes downregulation affects cell growth, cell motility and gene expression in lung cancer cells. Mol Cancer 7:87 doi:10.1186/1476-4598-7-87

[49] Su AI, Wiltshire T, Batalov S, Lapp H, Ching KR, Block D, Zhang J, Soden R, Hayakawa M, Kreiman G, Cooke MP, Walker JR, Hogenesch JB (2004) A gene atlas of the human and mouse protein encoding transcriptomes. Proc Natl Acad Sci USA 101: 6062-6067

[50] Hempel J, Kraut A, Wymore T (2009) Gamma glutamyl semialdehyde dehydrogenase: Simulations on native and mutant forms support the importance of outer shell lysines. Chem-Biol Interact 178:75-78

[51] Perozich J, Nicholas H, Wang, B-C, Lindahl R, Hempel J (1999) Relationships within the aldehyde dehydrogenase extended family. Protein Science 8:137-146

[52] Downes JE, Holmes RS (1994) Differential corneal sensitivity to ultraviolet light among inbred strains of mice. Cornea 13:67-72.

[53] Vasiliou V, Pappa A, Petersen DR (2000) Role of aldehyde dehydrogenases in endogenous and xenobiotic metabolism. Chem-Biol Interact 129:1-19.

Table 1: Aldehyde dehydrogenase (ALDH3A) genes and enzymes examined

GenBank mRNA (or cDNA) IDs identify previously reported sequences or predicted sequences (see http://www.ncbi.nlm.nih.gov/Genbank/); UNIPROT refer to UniprotKB/Swiss-Prot IDs for individual ALDHs (see http://kr.expasy.org). ALDH sequences are provided by the above sources. Vertebrate ALDH3A (ALDH3A1 and ALDH3A2) protein sequences were obtained from blast analyses of vertebrate genome sequences National Center for Biotechnology Information web tools (http://blast.ncbi.nlm.nih.gov/Blast.cgi) and rat ALDH3A1 [4] and ALDH3A2 [9] sequences. Predicted exon/intron locations and gene sizes were obtained by BLAT interrogations of vertebrate genomes using the predicted ALDH sequences and UC Santa Cruz web tools (http://genome.ucsc.edu). 


\begin{tabular}{|c|c|c|c|c|c|c|c|c|}
\hline Animal & Species & ALDH Gene & RefSeq miNA /Predicted^ & Amine atids & Chromosomal coordinates & Gene Size & Coding & Unipret ID \\
\hline & & & & & & (strane) & exons & \\
\hline Heman & Homo sapiens & 3A1 & NP_000582.3 & 453 & $17: 19,582,228-19,589,034$ & 6.807 (-ve) & 10 & P30838 \\
\hline Orangutan & Pango pygmaeus abelī & 3A1 & XP_002834247 & 453 & $17: 7,479,940-7,486,748$ & 6.809 (-ve) & 10 & na \\
\hline Rhesus menkey & Mocaca mulatto & 3AI & XP_001102220* & 453 & $16: 19,254,826-19,261,848$ & 7,023 (-ve) & 10 & na \\
\hline Narmaset & Collehrix jacthus & 3A1 & $X P_{-} 002748120^{\wedge}$ & 453 & $5: 77,143,814-77,150,337$ & 6.524 (-ve) & 10 & na \\
\hline Nouse & Mos musculus & 3A1 & $8 C 150677^{\circ}$ & 453 & $11,51,022,244-61,031,916$ & 9,673 (twe) & 10 & 947739 \\
\hline Rat & Rattus norvegicus & 3A1 & NP_114178.1 & 453 & $10: 47,368,564-47,374,585$ & $6,022(+v e)$ & 10 & P11883 \\
\hline Guinea Pig & Covia parcellos & 3AI & ENSCPOTOOOOC015825* & 453 & Contig71:688,016-593,637 & 5,622 (-ve) & 10 & na \\
\hline Dog & Canisfamilianis & 3AI & NM_001082420 & 453 & $5,43,466,510-43,474,545$ & $8,035($ twe $)$ & 10 & A3ค536 \\
\hline Horse & Equess caballus & 3A1 & XP_001918234A & 452 & $11.58,772,116-58,778,729$ & $6,614($ twe $)$ & 10 & na \\
\hline Cow & Bos towns & 3AI & NP_001159985 & 453 & $19: 34,796,256-34,802,049$ & $5,794(+\infty e)$ & 10 & no \\
\hline Cat & Felix creus & 3AI & Contie151381_2.1^ & 453 & Contie151381:66,101-72,175 & 6,075 (-ve) & 10 & na \\
\hline Opessum & Monodelohis domestica & 3AI & XP_001372749^ & 462 & $2: 518,942,352-518,961,160$ & 18,8009 (-ve) & 9 & no \\
\hline Platypes & Ormitharymchus anatinus & $3, A 1$ & XP_001508369A & 453 & Uetra69:171,875-181,973 & 10,221 (-ve) & 9 & no \\
\hline Haman & Homo sapiens & $3, A 2$ & NP_C00373.1 & 485 & $17: 19,492,877-19,515,861$ & 22,985 (twe) & 10 & P51648 \\
\hline Orangutan & Pango pygmaeus abelĩ & 3A2 & NM_001131237 & 485 & $17: 7,384,858-7,412,594$ & 27,737 (twe) & 10 & na \\
\hline Rhesas merkey & Macacu mulatta & 3,42 & XP_001101304^ & 485 & $16: 19,163,302-19,185,793$ & 22,492 (twe) & 10 & ASOHHB \\
\hline Marmaset & Collehrix jacthus & $3, A 2$ & $x P_{-} 0027<8108^{\wedge}$ & 485 & $5: 77,054,299 \cdot 77,082,410$ & 28,112 (twe) & 10 & na \\
\hline Nouse & Mos mosculus & $3, A 2$ & NM_C07437 & 484 & $11.51,058,257-61,080,629$ & 22,373 (-ve) & 10 & P47740 \\
\hline Rat & Rattus norvegicus & $3, A 2$ & NP_113119 & 484 & $10: 47,404,346-47,420,947$ & 16,602 (-ve) & 10 & P30839 \\
\hline Guinea pis & Covis parcellos & $3, A 2$ & ENSCPOTOOOOC013925* & 481 & Contig71:634,338-658,061 & 23,724 (twe) & 9 & no \\
\hline Dog & Conis familianis & $3 A 2$ & PP_536556^ & 484 & $5 \times 43,521,358-43,539,078$ & 17,721 (-ve) & 10 & no \\
\hline Horse & Eques caballes & $3 A 2$ & $x P \_001503562^{\wedge}$ & 594 & $11: 57,639,505 \cdot 57,662,302$ & 28,958 (-ve) & 11 & na \\
\hline Cow & Bas touns & 3.92 & NP_001095454 & 485 & $19: 34,839,902-34,851,760$ & 11,859 (-ve) & 10 & na \\
\hline Cat & Felix cutus & 3.92 & ENSFCATOOOCOC005181* & $450^{2}$ & Contie151381:1,268-8,073 & $13,688(+\sqrt{e})^{2}$ & $9^{2}$ & na \\
\hline Opessum & Monodelohis domestics & $3 A 2$ & $X P_{-} 001365258^{\wedge}$ & 507 & $2: 519,102,420-519,137,640$ & 35,221 (-ve) & 10 & na \\
\hline Platypess & Orvitharymchus anstinus & $3 A 2$ & ENSOANT00000020116^^ & 470 & Utera59:122,029-136,432 & 14,404 (twe) & 10 & na \\
\hline Chicken & Galls gailus & $3 A 2$ & NP_C01006223 & 490 & $19: 6,791,454-6,794,935$ & $3,482(+v e)$ & 9 & Q5ZLE2 \\
\hline Frag & Xenopus tropictís & $3 A 2$ & NP_C01016537 & 485 & Scaffold $721,185,178-1,196,603$ & 11,425 (-ve) & 10 & na \\
\hline \multirow[t]{2}{*}{ Zebrafish } & Danio rerio & $3, A 2.1$ & NP_997814' & 488 & $21 \times 0,884,680-40,915,474$ & 30,795 (-ve) & 10 & ATYYFA' \\
\hline & Danio revic & $3 ., 2.2$ & NP_997814' & 488 & $21 * 0,587,005-40,617,889$ & 30,794 (twe) & 10 & ATYYFA' \\
\hline Tetraodon & Tetraodan nigrovinidis & $3 A 2$ & CSTENT10018876001^ & 529 & $78,245,357-8,252,752$ & 7,385 (-ve) & 10 & na \\
\hline fugu: & Takifugu rutripes & $3 A 2$ & ENSTRUTDOOC0003183:4*4 & $472^{+}$ & $U_{n}^{5}: 142,311,988-142,315,606$ & $3.619(+v e)$ & 94 & no \\
\hline Stickleback & Gosterastews oculeatus & $3 . A 2$ & ENSGACTO0000027123^ & 478 & VII: $19,058,006-19,054,550$ & 6,545 (-ve) & 10 & na \\
\hline Medaka & Oryzias latipes & $3, A 2$ & ENSCRLTO0000003139^ & 493 & $148,460,321-8,469,158$ & 8,838 (-ve) & 10 & no \\
\hline Nematode & Coenarhabditis elegons & 3 & NM_071144 & 437 & $v: 1,996,109-1,999,581$ & 3,405 (-ve) & 6 & no \\
\hline
\end{tabular}

Table 2: Aldehyde dehydrogenase ( $A L D H 3 B$ ) genes and enzymes examined

GenBank mRNA (or CDNA) IDs identify previously reported sequences or predicted sequences (see http://www.ncbi.nlm.nih.gov/Genbank/); UNIPROT refer to UniprotKB/Swiss-Prot IDs for individual ALDHs (see http://kr.expasy.org). ALDH sequences are provided by the above sources. Vertebrate ALDH3B (ALDH3B1 and ALDH3B) protein sequences were obtained from blast analyses of vertebrate genome sequences National Center for Biotechnology Information web tools (http://blast.ncbi.nlm.nih.gov/Blast.cgi) and rat ALDH3B1 [12] and ALDH3B2 [14] sequences. Predicted exon/intron locations and gene sizes were obtained by BLAT interrogations of vertebrate genomes using the predicted ALDH sequences and UC Santa Cruz web tools (http://genome.ucsc.edu). 


\begin{tabular}{|c|c|c|c|c|c|c|c|c|}
\hline Animal & Species & ALDH & RefSeq mRNA /Predicted^ & Amine atids & Chromosomal coordinates & Gene Size & Coding & Unipret ID \\
\hline & & Gene & & & & (strand) & exons & \\
\hline \multirow[t]{2}{*}{ Hesman } & Homo sapiens & 391 & BCo13584 & 468 & $11: 67,539,3444-67,551,956$ & 12,513 (+ve) & 10 & P43353 \\
\hline & & 392 & NP_000586.2 & 385 & $11: 67,187,265-67,190,741$ & 3,477 (-ve) & 7 & P48448 \\
\hline \multirow[t]{2}{*}{ Chimpanzee } & Pan trogiodytes & 391 & ENSPTRTDCOCOCO07417 $7^{x x}$ & 468 & $11,56,232,082-66,245,136$ & 13,055 (+ve) & 9 & na \\
\hline & & 392 & ENSPTRTDOC00045258nx & 384 & $11: 56,158,638-66,162,590$ & 3,953 (-ve) & 8 & na \\
\hline \multirow[t]{2}{*}{ Orangutan } & Pango pygmoeus abelii & 391 & ENSPPYT00000003575^ג & $415^{x}$ & $118,105,491-8,114,867^{1}$ & $9,377^{2}$ (-ve) & $8^{2}$ & na \\
\hline & & 392 & chr11.117.1.1. & $375^{x}$ & $118,253,496-8,256,960^{2}$ & $3,465^{x}(+$ ve $)$ & $7^{2}$ & na \\
\hline \multirow[t]{2}{*}{ Rhesus merkey } & Macaca mulatte & 391 & $X P_{-} 001103842^{\wedge}$ & 468 & $14,6,693,135-6,705,696$ & $12,552($-ve) & 9 & na \\
\hline & & 392 & ENSMM $\int T 00000026055^{\wedge}$ & 385 & $145,790,595-6,794,458^{2}$ & $3,473^{x}($ twe $)$ & $7^{2}$ & na \\
\hline \multirow[t]{2}{*}{ Narmoset } & Collehrix jacthos & 391 & $X P_{-} 002755686^{3}$ & $285^{\prime}$ & $11: 123,522,170-123,536,620^{\prime}$ & 14,451 (twe) & $7^{3}$ & na \\
\hline & & 392 & Chr11.13.129^ & $225^{+}$ & $11: 123,450,401-123,451,610^{+}$ & $1,210(-v e)^{*}$ & $4^{4}$ & na \\
\hline \multirow[t]{2}{*}{ Mouse } & Mus masculus & 391 & $8 C 046597^{\circ}$ & 468 & $19: 3,913,897-3,923,900$ & 10,004 (-ve) & 9 & aboveso \\
\hline & & 392 & $6 C 100370^{\prime}$ & 479 & $19: 3,972,576-3,981,189$ & 8,614 (twe) & 10 & na \\
\hline \multirow[t]{2}{*}{ Rat } & Rattus nervegicus & 391 & $8 c 083850^{\circ}$ & 468 & $1205,438,748-206,449,646$ & 10,899 (-ve) & 9 & $05 \times 142$ \\
\hline & & 392 & ENSRNOTO000002Е054A & 405 & $1205,550,307-206,553,421$ & 3,115 (twe) & 8 & na \\
\hline \multirow[t]{2}{*}{ Guinea Pis } & Covis parcellos & 391 & ENSCPOTOOOOOOO23180* & 468 & Contie $42: 8,154,009-8,163,573$ & 9,565 (twe) & 9 & na \\
\hline & & 392 & ENSCPOTOOOOOOO02557* & 460 & Contie $42: 8,107,562-8,111,470$ & 3,909 (-ve) & 9 & no \\
\hline \multirow[t]{2}{*}{ Dog } & Conis familian's & 391 & XP_533211^ & 468 & $18.52,828,356 \cdot 52,839,937$ & 11,572 (-ve) & 9 & na \\
\hline & & 392 & ENSCAFTOOCO0017868* & $233^{5}$ & $18: 52,883,871-52,885,936^{5}$ & $2,055^{3}$ (twe) & $5^{5}$ & na \\
\hline \multirow[t]{2}{*}{ Horse } & Equess cabalies & 391 & $X P_{-} 001498641^{\wedge}$ & 468 & $12: 27,399,098-27,412,262$ & 13,165 (twe) & 9 & na \\
\hline & & 392 & ENSECATOOOO0006191^ & 461 & $12: 27,34,081-27,348,172$ & 4,092 (-ve) & 10 & no \\
\hline \multirow[t]{2}{*}{ Cow } & Bas towns & 391 & BC147958' & 468 & $29 \times 47,597,154-47,610,539$ & 13,385 (-ve) & 9 & QUPAO \\
\hline & & 392 & ABG67108' & 319 & $29 \times 47,459,517-47,463,844$ & 4,228 (-ve) & 7 & na \\
\hline \multirow[t]{2}{*}{ Cot } & Felix catus & 391 & scaffald_101138.001.1n & 433 & scaffold101138:41,262-54,588 & 13,327 (twe) & 9 & na \\
\hline & & 392 & scaffold__135367_2.1^ & $142^{3}$ & scaffold $135347: 28,737-33,205^{\prime}$ & $4,469^{7}$ (-ve) & $3^{\prime}$ & na \\
\hline Opessum & Monodelghis domestica & 391 & $X P \_001362651^{\wedge}$ & 465 & $\operatorname{Un}^{6}: 7,515,103-7,631,311$ & 5,708 (twe) & 8 & na \\
\hline \multirow[t]{2}{*}{ Chicken } & Gollus goîus & 391 & $X P \_426371^{\wedge}$ & 496 & $5: 79,353-85,060$ & 5708 (twe) & 10 & na \\
\hline & & 392 & thr5.005.1^a & 40 & $5: 70,087-78,443$ & 8,357 (twe) & 10 & na \\
\hline Frag & Xenopus trapictîs & 391 & NP_001120622 & 469 & Scaffold1 $331: 29,673-49,585$ & 19,913 (twe) & 9 & $n$ \\
\hline Zebrafish & Donio reric & 391 & NP_775328 & 473 & $3: 31,432,265-31,439,644$ & 7,379 (twe) & 9 & na \\
\hline Tetraedion & Teeraodan nigrovinidis & 391 & CAG05951' & 537 & $\operatorname{Un}^{6}=5,227,801-5,231,123$ & 3,323 (-ve) & 7 & na \\
\hline Fugu & Takifugu rutripes & 391 & NP_C01153657* & 511 & Un $6: 335,405,772-336,414,383$ & $8,612($-ve) & 13 & na \\
\hline Stickleback & Gosterastess aculeotus & 391 & ENSGACT00000007269^ & 494 & $x: 1,354,585-1,360,263$ & 5,679 (twe) & 10 & na \\
\hline Medaka & arycias latipes & 391 & ENSCRLTO00000021685^ & 471 & $8: 25,485,641-25,491,169$ & $5,529(-v e)$ & 10 & na \\
\hline
\end{tabular}

Table 3: Key aldehyde dehydrogenase (ALDH) amino acid residues for mammalian ALDH3 sequences.

Sequences examined include: human ALDH3A1 (human 3A1); rat ALDH3A1 (rat 3A1); COW ALDH3A1 (cOW 3A1); opossum ALDH3A1 (opossum 3A1); human ALDH3A2 (human 3A2); rat ALDH3A2 (rat 3A2); opossum ALDH3A2 (opossum 3A2); chicken ALDH3A2 (chicken 3A2); zebrafish ALDH3A2 (zebrafish 3A2); human ALDH3B1 (human 3B1); human ALDH3B2 (human 3B2); and C.elegans ALDH3-like sequence (elegans 3). Identification of predicted key catalytic and structural amino acid residues is based on 3D structural studies for rat ALDH3A1 [27]. S refers to substrate. See Figure 1 for the complete amino acid sequences for human and rat ALDHs. 


\begin{tabular}{|c|c|c|c|c|c|c|c|c|c|c|c|c|c|}
\hline Predicted & human & rat & cow & opessum & human & rat & cow & opessum & chicken & rebrafish & human & human & elegans \\
\hline function & 3.A1 & $3, A 1$ & 3.A1 & 3,41 & 3,02 & 3,02 & 3,02 & 3,42 & 3,42 & 3,02 & 381 & 382 & 3 \\
\hline \multirow[t]{2}{*}{ sbinding } & $\operatorname{Chu} 210$ & Gha210 & $\cos 210$ & Gu210 & Gu2207 & Gu207 & Gu207 & Gha207 & Gus 210 & Gu208 & Gu210 & Gu129 & Gu210 \\
\hline & $\cos 244$ & $\operatorname{crs} 244$ & $\mathrm{c} \times 244$ & $c \times 244$ & $c \times 241$ & $c \times 241$ & $\operatorname{cr} 241$ & $c_{n} 241$ & $\cos 244$ & $c_{n} 241$ & $c_{1} 244$ & $C_{n 263}$ & $c_{2} 244$ \\
\hline catalysis & Asn 115 & $A \sin 115$ & Asn 115 & $A \sin 115$ & Assn112 & $A \sin 112$ & $A \sin 112$ & $A \sin 112$ & $A \sin 115$ & Asn116 & Asn112 & $A \sin 34$ & Asn116 \\
\hline dycine & Gyr106 & Gyne6 & Grye6 & Gly106 & Gly103 & Gly 103 & Gin103 & Gin103 & Gly 106 & Gin104 & Gyic6 & Gly 25 & Gin106 \\
\hline residues & Gly 132 & Gly 132 & Gly 132 & Gly 132 & Gly 129 & Gly 129 & Gly 129 & Gly 129 & Gly 132 & Gly 130 & $\operatorname{Cll} 132$ & Gly51 & $\operatorname{Gin} 132$ \\
\hline chain & Gir168-9 & Gly168-9 & Gly168-9 & Gly168-9 & Gly165-6 & Gly165-6 & Gly165-6 & Gly165-6 & Gir168-9 & Gly $166-7$ & Gly168-9 & Gly $87-8$ & Gly $168-9$ \\
\hline folting & G)188 & G)188 & G)188 & G)188 & Gly185 & Giv185 & Gly185 & Gly185 & G)188 & Cly186 & C)188 & Ginno7 & G)188 \\
\hline \multirow[t]{7}{*}{ roles } & $6 / 212-3$ & Gly212-3 & Gly $212-3$ & Gly $212-3$ & $61 y 209-10$ & Gly209-10 & Gly209-10 & Gly209-10 & $61 y 212-3$ & Gly210-1 & Goly212-3 & Gly $131-2$ & $61 / 212-3$ \\
\hline & Gly 241 & Gly 241 & Gly 241 & Giv241 & Giy238 & Gly238 & Gly238 & Glp238 & Gly 241 & Gip239 & Gly 241 & Gly 160 & Gly241 \\
\hline & Giy307 & Giy307 & Gly 307 & Gly 307 & Gly 304 & Gly304 & Gly304 & Gly 304 & Cly 307 & Gly 305 & Coy 307 & Gly226 & Glyses \\
\hline & Gly 337 & Gly337 & Gly337 & Gly337 & Gly334 & Gly334 & Gly334 & Gly334 & Gir 337 & Gly335 & Gly 337 & Gly251 & Gor 340 \\
\hline & G) $3844-5$ & Gly $384-5$ & Gly $384-5$ & Gly384-5 & Gly $381-2$ & Gly $381-2$ & Cly381-2 & Goly381-2 & Gly $384-5$ & Gly $382-3$ & Gly384-5 & Gly 263 & Gly $387-8$ \\
\hline & Gly $403-4$ & Clyse3-4 & Gly $403-4$ & Cly403-4 & Gly $460-1$ & Glyateo-1 & Gly4c0-1 & Glyse0-1 & Glyse3-4 & Gly401-2 & Gly $403-4$ & Gly $322-3$ & Gly $406-7$ \\
\hline & Gly409 & Glyates & Glyac9 & Gly 409 & Glyse6 & Gly406 & Ghrac6 & Gly4e6 & Gly4c9 & Glyate7 & Clyac9 & $61 / 328$ & Gly 412 \\
\hline conserved & Pro104 & Pro104 & Pro104 & Pro104 & Pro101 & Pro101 & Pro101 & Pro101 & Pro104 & Pro102 & Pro104 & Pra23 & Pro104 \\
\hline proline & Pro318 & Pro318 & Pra318 & Pra318 & Pra315 & Pro315 & Pra315 & Pro315 & Pro318 & Pra316 & Pro318 & Pra237 & Pro322 \\
\hline residues & Pra341 & Pra341 & Pra341 & Pro341 & Pras38 & Pra338 & Pras38 & Pro338 & Pra341 & Pra339 & Pra341 & Praz60 & Pra344 \\
\hline stem & Cly 188 & Cyys8 & G)ys8 & Cly188 & Cly185 & Gly185 & Gly185 & Coy185 & Gly188 & Cly 186 & Gly 188 & Gin107 & Cly 188 \\
\hline of active & Gily212 & Gly 212 & $6 / 212$ & Gol 212 & Giv209 & $61 / 209$ & Gly209 & $6 / 209$ & $6 / 212$ & Gily210 & Gely212 & Gly131 & Gelp212 \\
\hline site & Che 334 & Che 334 & Che334 & Che 334 & Che 331 & Cha331 & Che331 & Che331 & Che334 & Che332 & Chu334 & Che253 & Clus37 \\
\hline funnel & Phe336 & Phe336 & Phe336 & Phe336 & Phe333 & Phe333 & Phe 333 & Phe 333 & Phe336 & Phe 334 & Phe 336 & Phe25s & Phe339 \\
\hline
\end{tabular}

Table 4: Major tissue distribution, substrates, functions and gene 'knock-out impacts for mammalian aldehyde dehydrogenases (ALDH)

3A1-ALDH3A1; 3A2-ALDH3A2; 3B1-ALDH3B1; 3B2-ALDH3B2 Reference sources are identified. See ALDH function review in [53].

\begin{tabular}{|c|c|c|c|}
\hline ALDH & Major tissue and & Substrate/Function & Gene Knock-out Impacts \\
\hline & cellular distribution & & \\
\hline \multirow[t]{5}{*}{$3 A 1$} & corneal epithelial cells $[36,37,44]$ & peroxidic aldehyde oxidation $[4,7,42,44]$ & UV-B sensitivity $[36,37,52]$ \\
\hline & lens epithelial cells [44] & generation of $\mathrm{NAD}(\mathrm{P}) \mathrm{H}$ for UV-B absorption $[7,36,37]$ & corneal dystrophy $[36,37,52]$ \\
\hline & stomach, trachea, lung, tongue [49] & C6+ aliphatic and aromatic aldehyde oxidation $[4,7,42]$ & \\
\hline & hepatoma [4] & cyclophosphamide and related cancer drug metabolism [47] & \\
\hline & & oxidative stress regulation and cell homeostasis [48] & \\
\hline $3 A 2$ & liver, kidney, adrenals [9,49] & fatty aldehyde oxidation $[9,10]$ & Sjogren-Larsson syndrome [10] \\
\hline 3B1 & kidney, lung $[12,49]$ & aldehyde oxidation [12] & \\
\hline 3B2 & salivary gland, adrenals [14,49] & aldehyde oxidation [13,14] & \\
\hline
\end{tabular}

\section{Figure 1: Amino acid sequence alignments for human and rat aldehyde dehydrogenases ALDH3 sequences (color version)}

See Table 1 for sources of ALDH sequences; $3 A 1$ Rat-rat ALDH3A1; 3A1 Humanhuman ALDH3A1; 3A2 Human-human ALDH3A2; 3B1 Human-human ALDH3B1; 3B2 Humanhuman ALDH3B2; * shows identical residues; : shows 2 conservative substitutions; . shows 3 conservative substitutions; bold font shows known or predicted exon junctions; predicted or known [27] $\beta$-sheet (grey shading) and $\alpha$-helix (yellow shading) secondary structures are shown; key residue identification is based on previous 3D studies of rat ALDH3Al and likely predicted roles for amino acid residues [27]: AS-active site residues: N,Asn114; E, Glu209 and Glu 333; and C, Cys243: initiation methionines are removed; $\alpha$-helices and $\beta$-sheets are identified as $\alpha A, \alpha B$ or $\alpha 10$ etc or $\beta 0$, $\beta 1$ etc, respectively, as identified by Liu and coworkers [27]; NP binding refers 
to coenzyme binding site; note the c-terminal helix predicted for the human ALDH3A2 sequence.

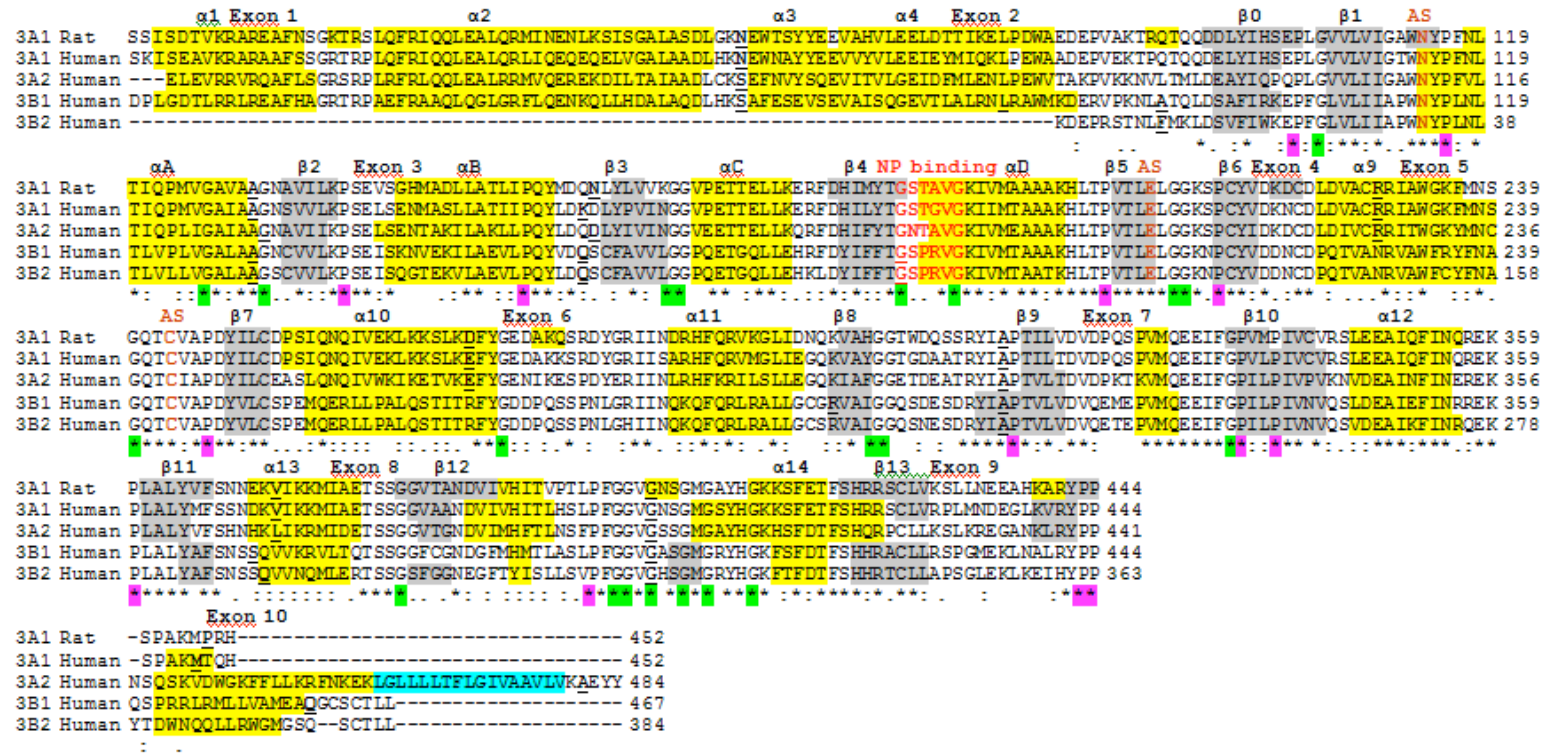

\section{Figure 2: Predicted transmembrane helices for human and chicken aldehyde} dehydrogenases ALDH3-like sequences (color version)

See Table 1 for sources of ALDH sequences. The TMHMM web tools of the Center for Biological Sequence Analysis, Technical University of Denmark TMHMM Server plots the probability of the ALDH sequence forming a transmembrane helix (0-1) (shown in red for the relevant amino acid sequences) (http://www.cbs.dtu.dk/services/TMHMM/). The predicted C-terminal transmembrane helices observed for human and chicken AL3A2 sequences are identified. Regions of the ALDH sequence predicted to be located inside or outside the membrane are shown in blue and pink, respectively. 


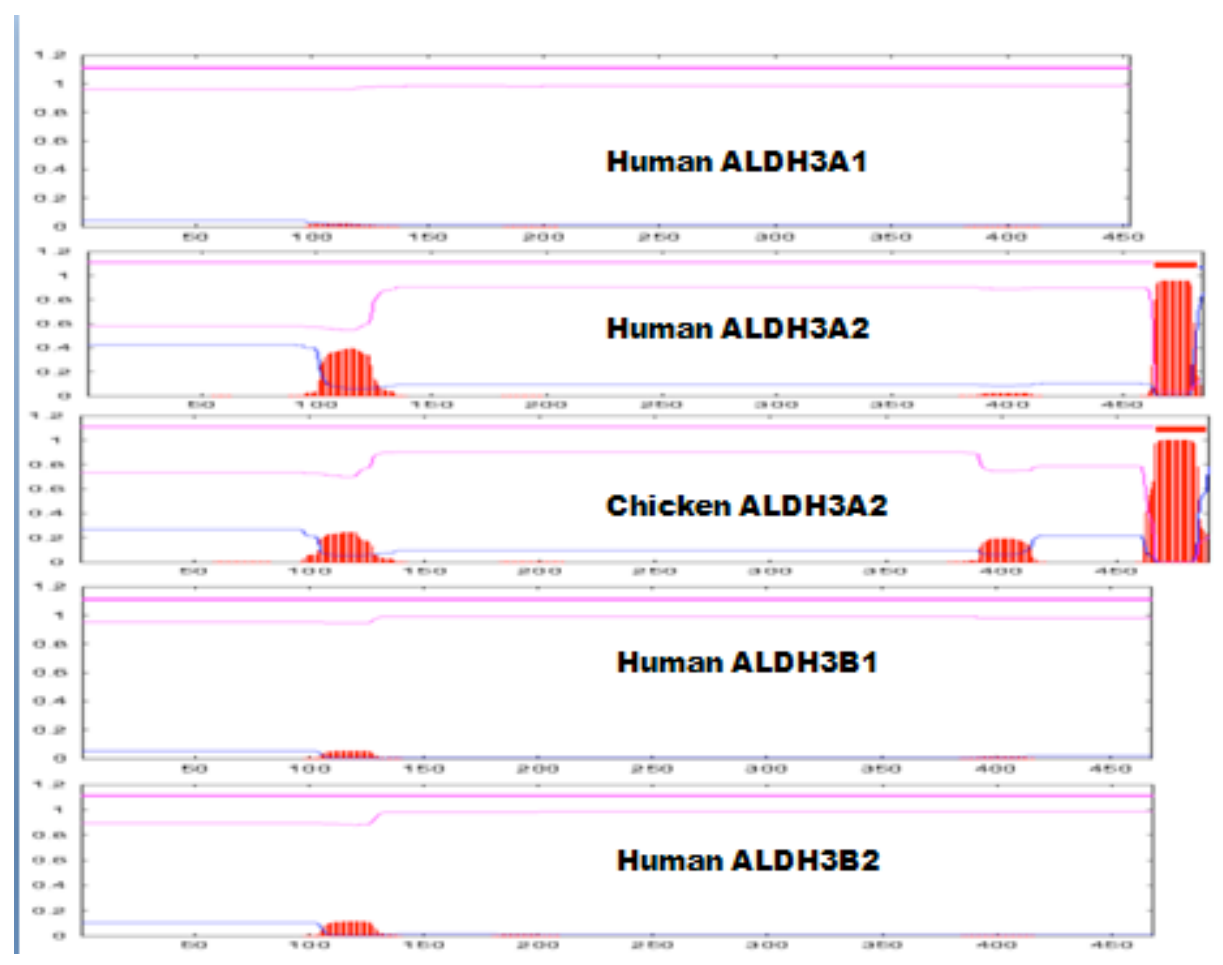

Figure 3: Predicted tertiary structures for human ALDH3A1, ALDH3A2, ALDH3B1 and ALDH3B2 sequences (color version)

The predicted tertiary structures were obtained using the SWISS MODEL web site (http://swissmodel.expasy.org/workspace) and the predicted or known amino acid sequences for human ALDH3A1, ALDH3A2, ALDH3B1 and ALDH3B2 (see Table 1); the rainbow color code describes the predicted 3-D structures from the $\mathrm{N}^{-}$(blue) to C-termini (red); the designation of the three domains is based on the rat ALDH3Al structure [27]. 


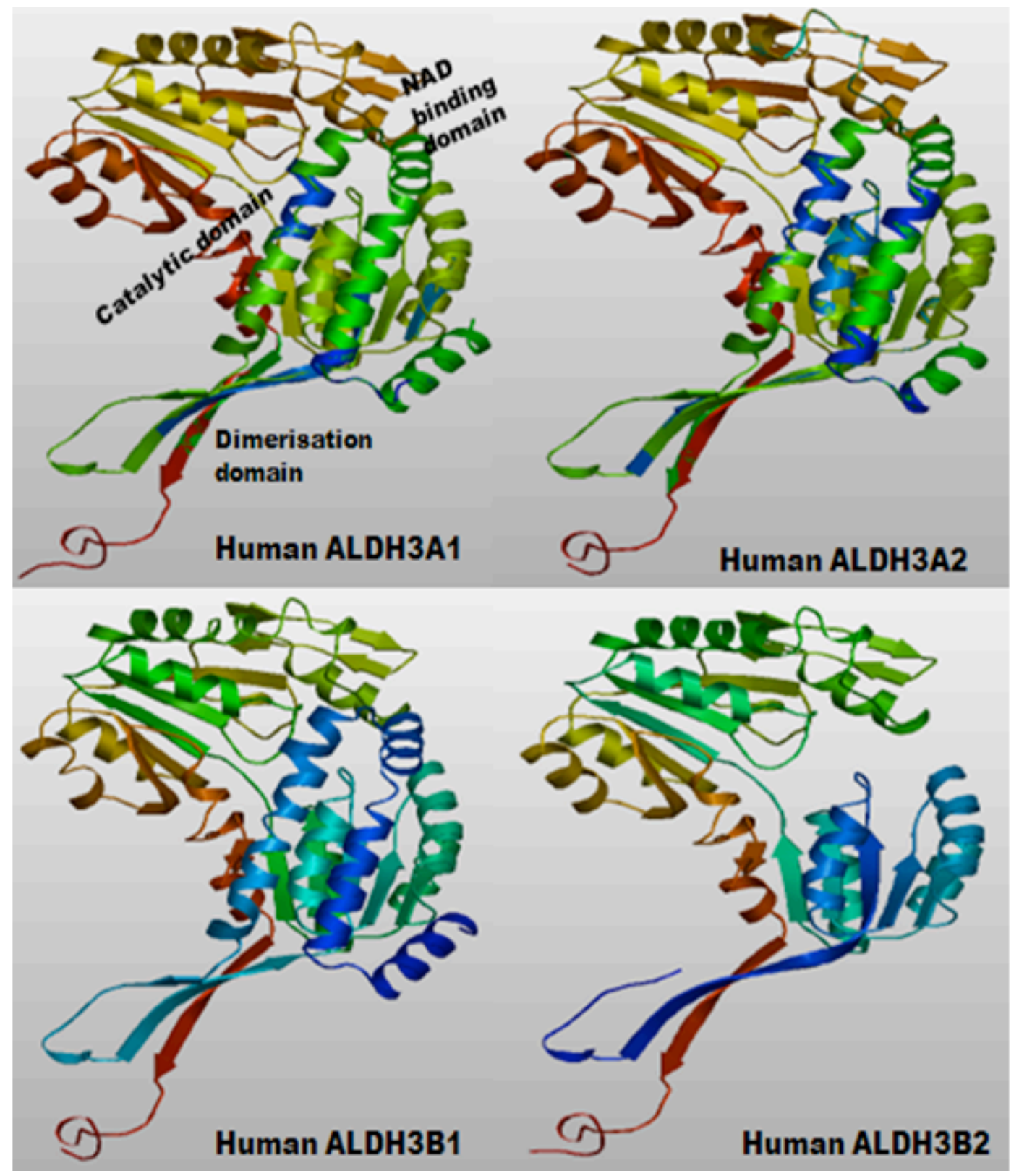

Figure 4: Proposed gene duplication events during the evolution of vertebrate aldehyde dehydrogenase ALDH3 (A) and phylogram of vertebrate and nematode aldehyde dehydrogenase ALDH3 sequences (B)

Each branch of the phylogram is labeled with the species name followed by an abbreviation of the gene name (3A1-ALDH3A1; 3A2-ALDH3A2; 3B1-ALDH3B1; 3B2ALDH3B2; and 3-C.elegans ALDH3-like) sequences. Note the clustering into three ALDH groups (ALDH3A1, ALDH3A2 and ALDH3) of sequences. A genetic distance scale is shown. The number of times a clade (sequences common to a node or branch) occurred in the bootstrap replicates are shown. Only replicate values of 90 or more which are highly significant are shown with 100 bootstrap replicates performed in each case. Note the significant separation of clades for the mammalian ALDH3A1, and vertebrate ALDH3A2 and ALDH3B sequences. The C.elegans sequence was used to 'root' the tree. 
A.

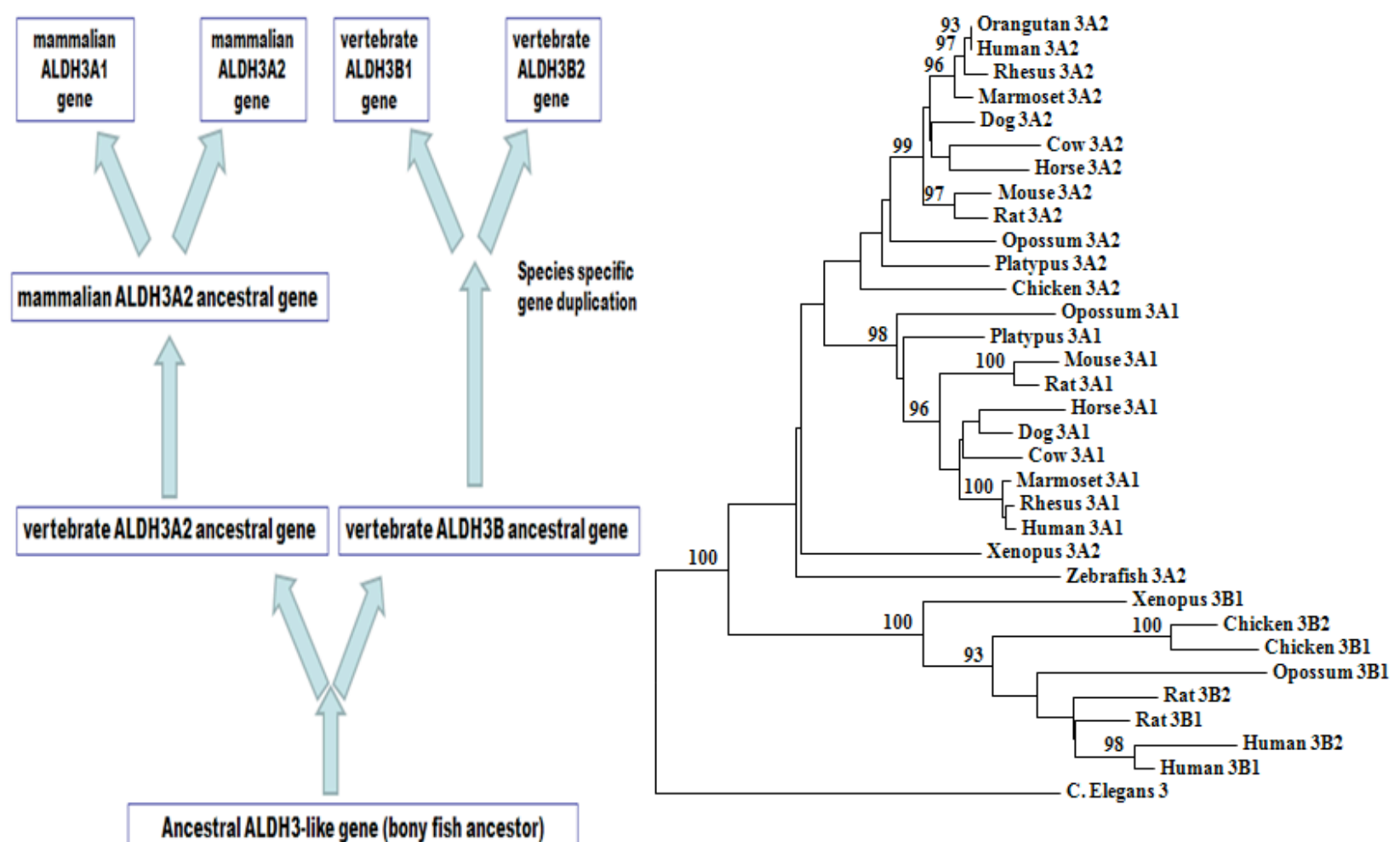

B.

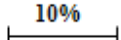




\section{Figure S1: Amino acid sequence alignments for human ALDH3B1 and vertebrate ALDH3B2 sequences}

See Table 2 for sources of ALDH3B sequences; 3B1 hu-human ALDH3B1; 3B2 huhuman ALDH3B2; 3B2 ch-chimpanzee ALDH3B2; $3 B 2$ rh-rhesus ALDH3B2; 3B2 ho-horse ALDH3B2; 3B2 ra-rat ALDH3B2; 3B2 mo-mouse ALDH3B2; 3B2 gp-guinea pig ALDH3B2; 3B2 ck-chicken ALDH3B2; * shows identical residues; : shows 2 conservative substitutions; . shows 3 conservative substitutions; bold font shows known or predicted exon junctions; predicted or known [27] $\beta$-sheet (grey shading) and $\alpha$-helix (yellow shading) secondary structures are shown; key residue identification is based on previous 3D studies of rat ALDH3A1 and likely predicted roles for amino acid residues [27]: AS-active site residues: N,Asn114; E, Glu209 and Glu 333; and C, Cys243: initiation methionines are removed; $\alpha$-helices and $\beta$-sheets are identified as $\alpha \mathrm{A}, \alpha \mathrm{B}$ or $\alpha 10$ etc or $\beta 0$, $\beta 1$ etc, respectively, as identified by Liu and coworkers [27]; NP binding refers to coenzyme binding site; note the c-terminal helix predicted for the human ALDH3A2 sequence.

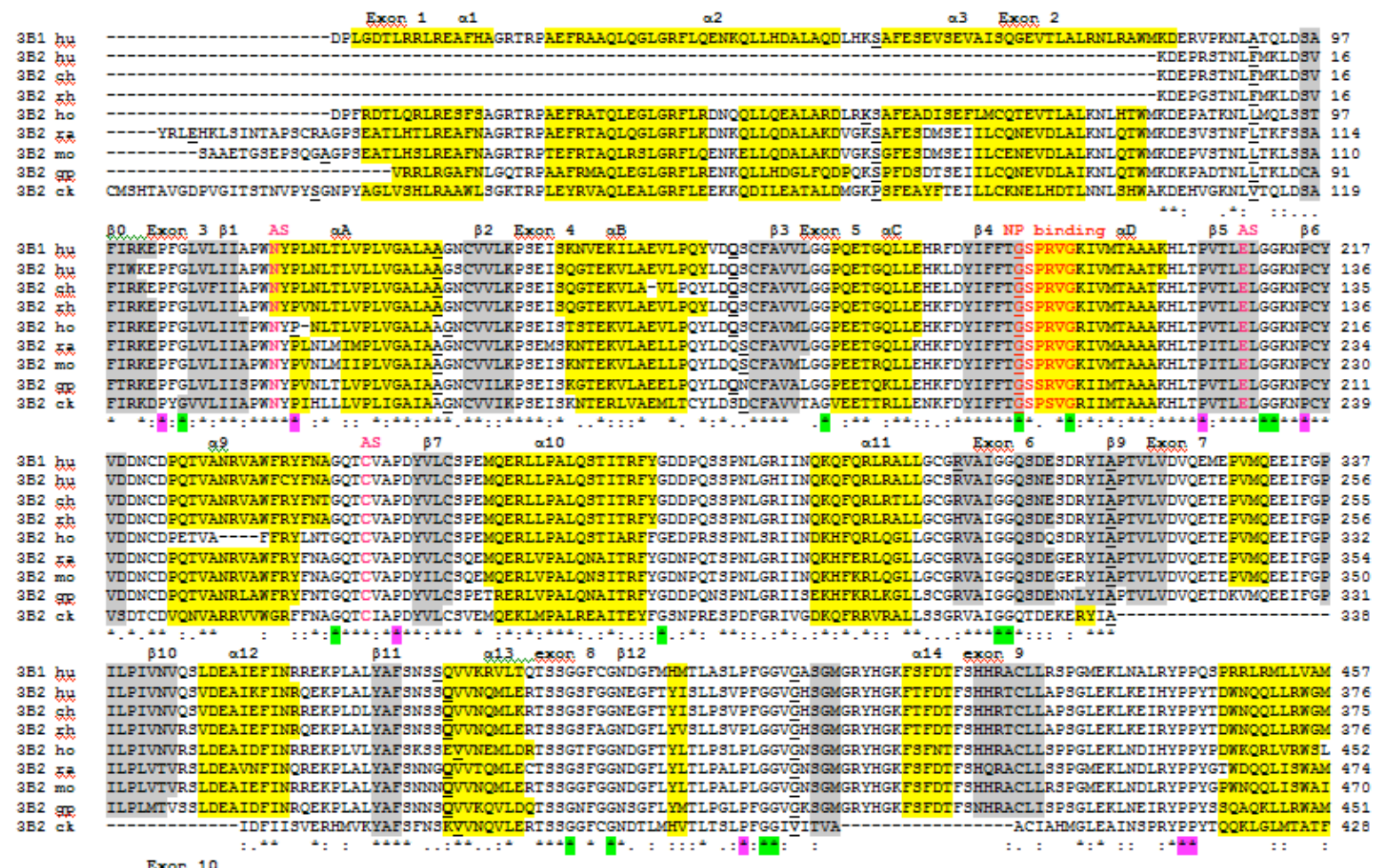
Exar, 10

$\begin{array}{lll}3 \mathrm{~B} 1 \mathrm{hu} & \text { EAQG-CSCTLI } 467 \\ 3 \mathrm{~B} 2 & \text { hu } & \text { GSQ---SCTLI } 384\end{array}$

3B2 sh GBQ---SCSLI 383

$3 B 2$ fh GSN---SCTLL 38

$3 B 2$ ho GPQ---SCTLI 460

3B2 If GSQ---BCTLI 482

3B2 mo GSR---SCTLL 47

3B2 GP RaH--BCTLL 459

$3 \mathrm{~B} 2 \mathrm{ck}$ EIRRKGTCTLL 439 